\title{
Prevalence and Type Distribution of Human Papillomavirus Recovered from the Uterine Cervix of Nigerian Women: A Systematic Review and Meta-Analysis
}

\author{
Auwal Idris Kabuga ${ }^{1,2 *}$, Ahmad Nejati ${ }^{1}$, Amanuel Godana Arero ${ }^{3}$, Somayeh \\ Jalilvand $^{1}$, Talat Mokhtari-Azad ${ }^{1}$, Shirin Shahbazi Sighaldeh ${ }^{4}$, Umma Hassan \\ Wali $^{5}$, Shohreh Shahmahmoodi ${ }^{1,5 *}$, Mohamed E. El Zowalaty ${ }^{6,7}$
}

\begin{abstract}
Background: Infection with an oncogenic type of human papillomavirus is a prerequisite for the development of precancerous cervical lesions and its subsequent progression to cervical cancer. With an alarming increase in the detection of other suspicious papillomavirus genotypes in both healthy and women with cervical lesions, there is a need for comprehensive data on cervical papillomavirus infection to address cervical cancer and other associated disease burden, especially in Sub-Sarahan Africa, where the bulk of the problem exists. The present study was conducted to develop comprehensive data on the prevalence and circulating genotypes of human papillomavirus in various risk categories in Nigeria. Methods: A systematic review and meta-analysis of peer-reviewed publications on cervical papillomavirus infection were performed. Relevant data were extracted from eligible studies published in PubMed, Web of Science, Embase, Scopus, and Google Scholar, from inception to July 31, 2019. The random-effect model was used to estimate the pooled prevalence. We identified 327 potential studies and pooled data from 18 studies, involving 5697 women aged 15-86 years. Results: The overall pooled prevalence of cervical papillomavirus infection was $42 \%$ (95\%CI: 30-54\%) in the general population and 37\% (95\%CI: 25-50\%) among women living with HIV/AIDS, with the predominance of genotypes $16,18,31,35,52,58$ and 45 . The highest prevalence was observed in teenagers and young adults and the second peak in women 50 years and above. Conclusion: The prevalence of cervical human papillomavirus infection is cumulatively high in Nigeria and HIV is a strong co-factor. We, therefore, strongly recommend the co-screening of human papillomavirus and cervical cancer and integration of the intervention strategy into the existing HIV-care guideline in Nigeria.
\end{abstract}

Keywords: Human papillomavirus- cervical cancer- risk factors- meta-analysis- Nigeria

Asian Pac J Cancer Prev, 21 (10), 2837-2846

\section{Introduction}

The link between human papillomavirus (HPV) and cervical cancer is one of the highest identified causative agents of cervical cancer in human cancerology, with almost all cases attributed to sexually acquired oncogenic genotypes, qualifying HPVs second after cigarette smoking as a risk factor for human cancers. Cervical cancer is considered as the fourth female cancer (Bray et al., 2018; Ferlay et al., 2019) and a common cause of cancer deaths in many parts of Sub-Saharan Africa. Cervical cancer is the second leading cause of cancer mortality in Nigeria (Ferlay et al., 2019).

Following the establishment of the Expanded Program on Immunization (EPI) in 1974, the world has recorded a great success in controlling many infectious diseases; the eradication of smallpox and a significant reduction in the burden of many but especially viral diseases, like poliomyelitis, measles, and rabies (Levine et al., 2011). Similarly, HPV-related cervical cancers and hepatitis B virus-induced liver cancers are effectively prevented using appropriate reliable vaccines. With effective screening and vaccination, every woman can be protected against cervical cancer.

${ }^{1}$ Department of Virology, School of Public Health, Tehran University of Medical Sciences, Tehran, Iran. ${ }^{2}$ Department of Medical Microbiology and Parasitology, Faculty of Clinical Sciences, College of Health Sciences, Bayero University, Kano, PMB 3011 Kano State, Nigeria. ${ }^{3}$ Students' Scientific Research Center, Tehran University of Medical Sciences, Tehran, Iran. ${ }^{4}$ Department of Reproductive Health, School of Nursing and Midwifery, Tehran University of Medical Sciences, Tehran, Iran. ${ }^{5}$ Food Microbiology Research Center, Tehran University of Medical Sciences, Tehran, Iran. ${ }^{6}$ Department of Clinical Sciences, College of Medicine, University of Sharjah, Sharjah 27272, UAE. 'ZZoonosis Science Center, Department of Medical Biochemistry and Microbiology, Uppsala University, Uppsala Se-75 123, Sweden.*For Correspondence: shahmahmoodi@tums.ac.ir,auwalkabuga76@gmail.com 
In Nigeria, there is poor awareness about HPV and its relationship with cervical cancer (Audu et al., 2014; Oluwasola et al., 2019) and no standardized data on HPV prevalence. This indicates that cervical cancer is neglected in the country, in terms of screening, prevention, and vaccination. Considering the population of women who are at risk of developing cervical cancer (over 50.3 million) in Nigeria, a country-specific HPV type distribution study is imperative. We conducted this systematic review and meta-analysis to provide comprehensive and representative data on prevalence, type distribution, and determinants of cervical HPV infection.

\section{Materials and Methods}

This study was conducted in compliance with the PRISMA guidelines and reports relevant to the outcome of interest included in the quantitative synthesis (Moher et al., 2009). The outcomes of interest include the prevalence of cervical HPV infection, risk factors, and circulating genotypes in Nigeria.

\section{Search strategy and data sources}

We performed a comprehensive search of databases to identify all relevant articles published on cervical HPV infection, including prevalence, risk factors, and distribution of the circulating genotypes in Nigeria. Databases explored were PubMed, Web of Science, Embase, Scopus, and Google Scholar, from inception to July 31, 2019, when the search was last updated. References of all selected studies were further screened for studies connected to HPV infection in the country.

\section{Inclusion and exclusion criteria}

Studies of any design published in English Language and peer-reviewed journals were included, with emphasis on adequate samples and enough data to determine the prevalence, distribution of HPV types, and determinants of cervical HPV infection. Only studies that checked for at least two clinically relevant HPV genotypes (e.g. 16 and 18) from the cervical specimen, using a molecular-based approach (e.g. PCR, HC, LiPA25) with a sample size of at least 30 were included in the final data synthesis. Thirteen studies were excluded based on duplication of data or study population (Schnatz et al., 2008; Clarke et al., 2011; Gage et al., 2012a; Akarolo-Anthony et al., 2013; Famooto et al., 2013; Musa et al., 2013; AdegbesanOmilabu et al., 2014; Akarolo-Anthony et al., 2014; Dareng et al., 2016; Manga et al., 2016; Nyengidiki and Athanasius, 2016; Adebamowo et al., 2018; Nyengidiki and Oranu, 2018), and two studies due to inadequate sample size or unclear results (Kolawole et al., 2015; Kolawole et al., 2016). Two studies comparing cervical sampling methods (Modibbo et al., 2017; Ajenifuja et al., 2018), and a study with no information about HPV types (Nejo et al., 2018) were further excluded. Finally, 18 studies were included in the data synthesis.

\section{Data extraction and quality assessment}

Pre-designed data extraction was performed and the following data; the name of the first author, publication year, the period of study, the geopolitical zone where the study was conducted, study site, age range, mean/ or median age of the participants, the total number included, number of positive, classification of cytological findings, method of detection, genotypes targeted for and predominant types identified as well as risk factors. Newcastle Ottawa scale for cross-sectional studies was used to assess the quality of the included studies.

\section{Statistical analysis}

A meta-analysis using the DerSimonian and Laird random effect model was performed to calculate the pooled prevalence estimates. The heterogeneity of the studies was assessed using Cochran's Q $\chi 2$ statistic and Higgins's method I ${ }^{2}$-statistic. Cochran's Q statistics $(\mathrm{P}<0.1)$ indicates a statistically significant variation among the studies, while $\mathrm{I}^{2}$-statistics quantifies the proportion of variance explained between studies heterogeneity. Meta-regression analysis was performed to check for a potential source of heterogeneity by considering the year of publication. Both funnel plot symmetry and Egger's regression asymmetry test and Begg rank correlation methods were used to evaluating the presence of publication bias. The outcome of sensitivity evaluation confirmed that our findings were robust and not one-study dependent. The pooled prevalence estimates of the infection range from $39 \%$ (95\% CI: $29-49 \%$ ) to $44 \%$ (95\%CI: $32-56 \%$ ) after single-study removal. We conducted subgroup analyses by administration divisions to provide summary estimates for various risk categories and methods of detection. For all analyses, Stata software (StataCorp, TX, USA, version 14.0) was used and a two-tailed $\mathrm{P}<0.05$ was considered statistically significant.

\section{Results}

The process of article selection is shown in Figure 1. Most of the studies were accomplished by PCR using DNA extracted from cervical samples, collected from 5,697 women aged 15-86 years from the six geo-political zones.

\section{Characteristics of the included studies}

All included studies were cross-sectional in design and the majority hospital-based and employed PCR techniques. Looking at the oncogenic and low-risk HPV types from the cervices of women aged 15 to 86 years, a wide range of prevalence $(4.9 \%-85.6 \%)$ was observed. The included studies were carried out from June 1999 to May 2017 and published between 2004 to 2019 as shown in Table 1.

\section{Heterogeneity and publication bias}

Studies were evaluated for potential publication bias by qualitative and quantitative approaches and the funnel plot showed the absence of publication bias (Figure 2). Absence of publication bias was also confirmed by Begg's rank correlation test $(\mathrm{p}=0.705)$ and Egger's weighted regression test (bias coefficient $=1.1595$ (95\% $\mathrm{CI}$ : -5.970982 to $8.289982 ; \mathrm{p}=0.735)$. Given a significant variation among the studies $\left(\mathrm{I}^{2}=99.2, \mathrm{p}<0.01\right)$, random effects model was applied to estimate the DerSimonian 


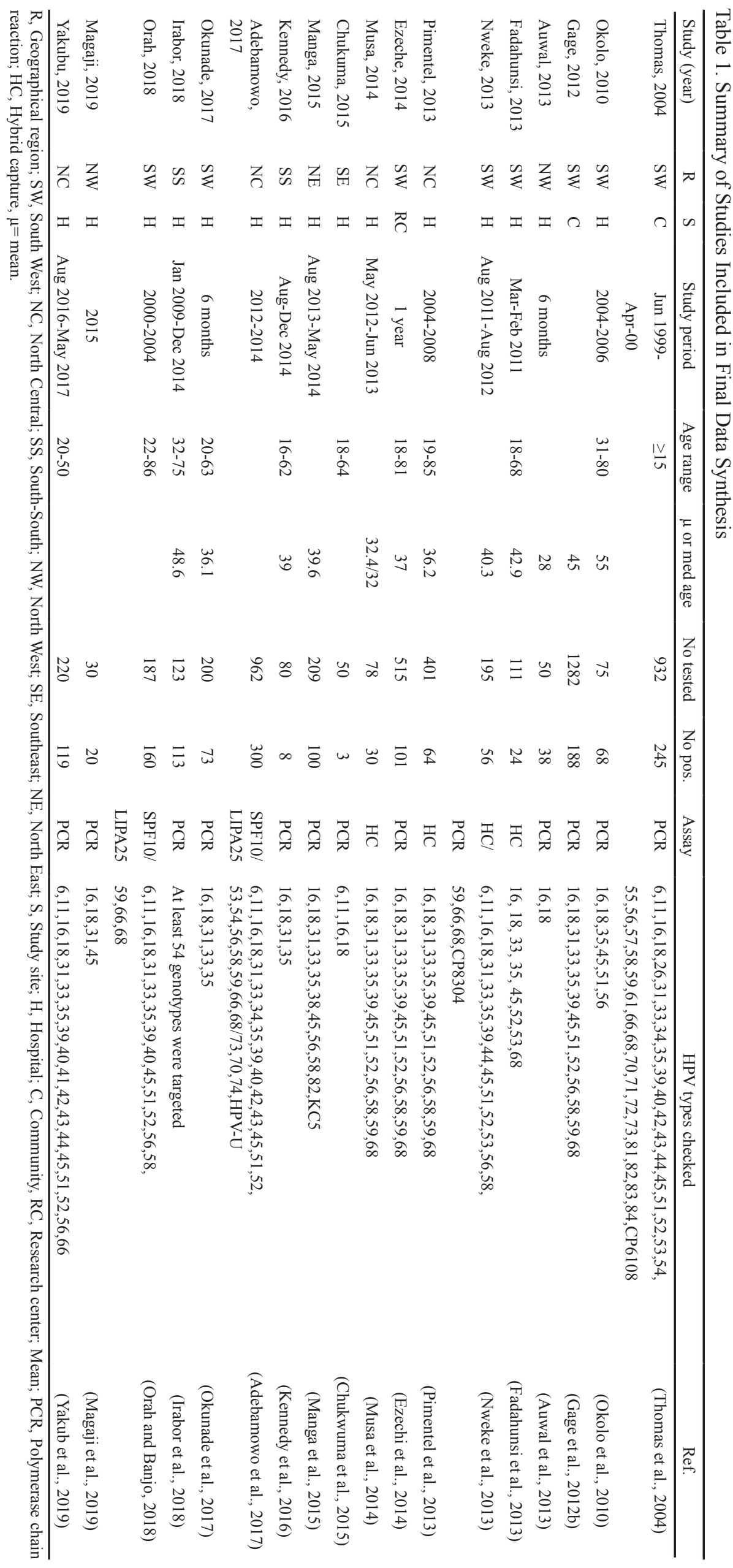


Table 2. Subgroup Analysis of cervical HPV Infection in Nigeria, 2019

\begin{tabular}{|c|c|c|c|c|c|}
\hline Characteristic & Category & No of studies & $\begin{array}{l}\text { Pooled prevalence } \\
(95 \% \mathrm{CI})\end{array}$ & $\mathrm{I}^{2}(\mathrm{P}$-value $)$ & $\begin{array}{c}\text { Difference } \mathrm{b} / \mathrm{w} \\
\text { subgroup } \chi^{2} \text { test } \mathrm{p} \text {-value }\end{array}$ \\
\hline \multirow[t]{3}{*}{ Overall } & - & 18 & $42(30-54)$ & $99.2(<0.01)$ & - \\
\hline & SW & 8 & $40(23-58)$ & $99.3(<0.01)$ & \\
\hline & $\mathrm{NC}$ & 4 & $35(20-49)$ & $97.3(<0.01)$ & \\
\hline \multirow[t]{4}{*}{ Zone } & SS & 2 & $51(-29-131)$ & $99.7(<0.01)$ & \\
\hline & NW & 2 & $73(63-83)$ & $0(0.38)$ & $99.2(<0.01)$ \\
\hline & SE & 1 & $6(1-13)$ & - & \\
\hline & $\mathrm{NE}$ & 1 & $48(41-550$ & - & \\
\hline \multirow[t]{3}{*}{ Excluding WLWHA } & - & 15 & $42(28-56)$ & $99.3(<0.01)$ & - \\
\hline & SW & 8 & $38(20-56)$ & $99.4(<0.01)$ & \\
\hline & $\mathrm{NC}$ & 2 & $19(13-24)$ & $77.3(0.04)$ & \\
\hline \multirow[t]{3}{*}{ Zone } & SS & 2 & $51(-29-131)$ & $99.7(<0.01)$ & $99(<0.01)$ \\
\hline & NW & 2 & $73(63-83)$ & $0(0.38)$ & \\
\hline & $\mathrm{NE}$ & 1 & $47(40-54)$ & - & \\
\hline \multirow[t]{2}{*}{ WLWHA } & - & 8 & $37(25-50)$ & $95.1(<0.01)$ & \\
\hline & Normal & 7 & $27(19-36)$ & $95.6(<0.01)$ & \\
\hline \multirow[t]{4}{*}{ Histology } & Abnormal & 9 & $66(52-81)$ & $94.1(<0.01)$ & \\
\hline & Ca cervix & 3 & $87(83-91)$ & $0(0.53)$ & \\
\hline & $\mathrm{CIN}-3$ & 2 & $57(21-94)$ & $0(0.81)$ & \\
\hline & $<30$ & 6 & $45(27-63)$ & $93(<0.01)$ & \\
\hline \multirow[t]{3}{*}{ Age (years) } & $30-39$ & 5 & $44(13-75)$ & $97.3(<0.01)$ & \\
\hline & $40-49$ & 5 & $38(8-67)$ & $78.6(<0.01)$ & \\
\hline & $\geq 50$ & 5 & $43(5-81)$ & $99.1(<0.01)$ & \\
\hline \multirow[t]{3}{*}{ Method of Detection } & PCR & 13 & $43(29-58)$ & $99.2(<0.01)$ & $99.2(<0.01)$ \\
\hline & $\mathrm{HC}$ & 3 & $24(13-36)$ & $87.2(<0.01)$ & \\
\hline & SPF10/LIPA25 & 2 & $58(5-112)$ & $99.7(<0.01)$ & \\
\hline
\end{tabular}

WLWHA, Women living with HIV/AIDs; SW, South West; NC, North Central, SS, South-South; NW, North West; SE, southeast; NE, North East; Ca cervix, cervical cancer; CIN, cervical intraepithelial neoplasia; PCR, polymerase chain reaction; HC, hybrid capture assay; $\mathrm{I}^{2}$, heterogeneity; CI, confidence interval.

Table 3. Type specific Prevalence of Cervical HPV Infection in Nigeria, 2019

\begin{tabular}{|c|c|c|c|c|c|c|c|c|c|}
\hline \multirow[t]{2}{*}{ Genotype } & \multicolumn{3}{|c|}{ Overall } & \multicolumn{3}{|c|}{ WLWHA } & \multicolumn{3}{|c|}{ Cervical cancer \& HGSILS } \\
\hline & $\begin{array}{l}\text { No of } \\
\text { studies }\end{array}$ & $\begin{array}{l}\text { Pooled prevalence } \\
\qquad(95 \% \mathrm{CI})\end{array}$ & $\mathrm{I}^{2 \%} \%(\mathrm{P})$ & $\begin{array}{l}\text { No of } \\
\text { studies }\end{array}$ & $\begin{array}{l}\text { Pooled prevalence } \\
\qquad(95 \% \mathrm{CI})\end{array}$ & $\mathrm{I}^{2 \%} \%(\mathrm{P})$ & $\begin{array}{l}\text { No of } \\
\text { studies }\end{array}$ & $\begin{array}{l}\text { Pooled prevalence } \\
\quad(95 \% \mathrm{CI})\end{array}$ & $\mathrm{I}^{2} \%(\mathrm{P})$ \\
\hline 16 & 14 & $27(18-35)$ & $95.9(<0.01)$ & 3 & $15(5-24)$ & $83.5(<0.01)$ & 3 & $51(33-69)$ & $\begin{array}{c}85.3 \\
(<0.01)\end{array}$ \\
\hline 18 & 14 & $23(15-31)$ & $95.2(<0.01)$ & 3 & $8(3-12)$ & $61.7(0.07)$ & 3 & $14(7-21)$ & $52.1(0.12)$ \\
\hline 31 & 11 & $15(9-21)$ & $94.6(<0.01)$ & 3 & $10(1-19)$ & $90.9(<0.01)$ & 3 & $3(0-5)$ & $34.3(0.22)$ \\
\hline 33 & 9 & $4(2-6)$ & $70.8(<0.01)$ & 3 & $7(1-12)$ & 79. $(0.01)$ & 3 & $1(0-3)$ & $0(0.76)$ \\
\hline 35 & 12 & $11(7-15)$ & $81.7(<0.01)$ & 3 & $19(14-24)$ & $18.4(0.29)$ & 3 & $8(1-14)$ & $64(0.06)$ \\
\hline 39 & 6 & $2(1-3)$ & $12.3(0.34)$ & 3 & $2(0-3)$ & $0(0.44)$ & - & - & - \\
\hline 45 & 10 & $6(4-8)$ & $55.3(0.02)$ & 3 & $8(2-13)$ & $71.8(0.03)$ & 3 & $9(5-13)$ & $14.5(0.31)$ \\
\hline 51 & 7 & $5(2-7)$ & $86(<0.01)$ & 3 & $5(-1-12)$ & $86.2(<0.01)$ & 3 & $2(1-5)$ & $30.8(0.24)$ \\
\hline 52 & 7 & $9(5-14)$ & $94.5(<0.01)$ & 3 & $11(-2-24)$ & $94.6(<0.01)$ & - & - & - \\
\hline 56 & 9 & $4(3-6)$ & $60.9(0.01)$ & 3 & $4(2-6)$ & $0(0.67)$ & 3 & $3(2-7)$ & $58.9(0.12)$ \\
\hline 58 & 6 & $8(3-13)$ & $92.7(<0.01)$ & 3 & $10(0-21)$ & $75.2(0.045)$ & - & - & - \\
\hline 59 & 5 & $2(1-3)$ & $46.5(0.11)$ & 3 & $4(0-7)$ & $50.9(0.15)$ & - & - & - \\
\hline 68 & 5 & $4(1-6)$ & $76.3(<0.01)$ & 2 & $3(1-6)$ & $0(0.54)$ & - & - & - \\
\hline Other types & 5 & $8(3-13)$ & $80.5(<0.01)$ & - & - & - & - & - & - \\
\hline
\end{tabular}

WLWHA, women living with HIV/AIDs; Other types include HPV-53, 70 \& 82; HGSILs, High grade squamous intraepithelial lesions; I², Heterogeneity; P, p-value; CI, Confidence interval. 


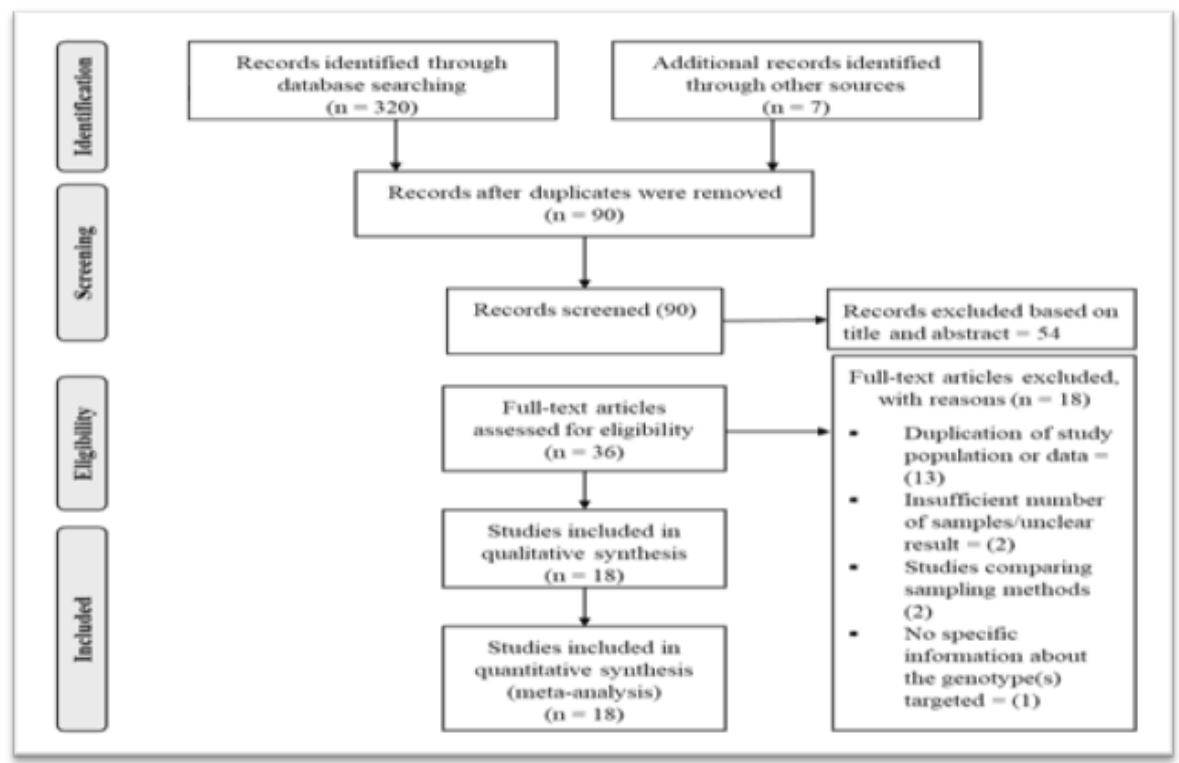

Figure 1. PRISMA Flowchart Showing Selection of the Eligible Studies on Cervical Papillomavirus Infection in Nigeria, 2019.

and Laird's pooled effect.

Overall pooled prevalence of cervical papillomavirus infection in Nigeria

The prevalence of cervical HPV infection was determined as the the proportion of positive cases of any HPV type expressed in percentage, giving an estimated pooled prevalence of $42 \%$ (95\%CI: $30-54 \%$ ) (Figure 3). As indicated in Table 2, the prevalence varies with geopolitical zone, population sub-unit, detection method, and histologic classification of cervical findings.

Estimated pooled prevalence in HIV positive women (HIV-HPV coinfection)

A cohort of studies conducted among HIV positive women was included and we performed subgroup analysis by HIV positivity, giving a pooled prevalence of $37 \%$ (95\%CI: $25-50 \%$ ). HIV was found to exert a strong effect on the acquisition of cervical HPV infection in Nigeria
$[\mathrm{OR}=2.34(95 \% \mathrm{CI}=1.36-4.02 \%): \mathrm{p}<0.01]$, as shown in Table 4.

Age-specific prevalence of cervical HPV infection in Nigeria

The prevalence of cervical HPV varies significantly among different age groups in Nigeria and shows bi-modal age peaks. The highest prevalence was estimated among teenagers $45 \%(95 \% \mathrm{CI}: 27-63 \%)$ and young adults $44 \%$ (95\%CI: $13-75 \%$ ) who were at the climax of their sexual activity, then a second peak $43 \%(95 \% \mathrm{CI}: 5-81 \%)$ in women 50 years and above.

\section{HPV type-specific prevalence}

Majority of the included studies paid emphasis on cancer-causing genotypes (Table 1). Although commonly reported types varied slightly by the study, HPV type 16 predominates with an overall pooled prevalence of $27 \%$ (95\%CI: 18-35\%), followed by type $18,31,35,52,58$,

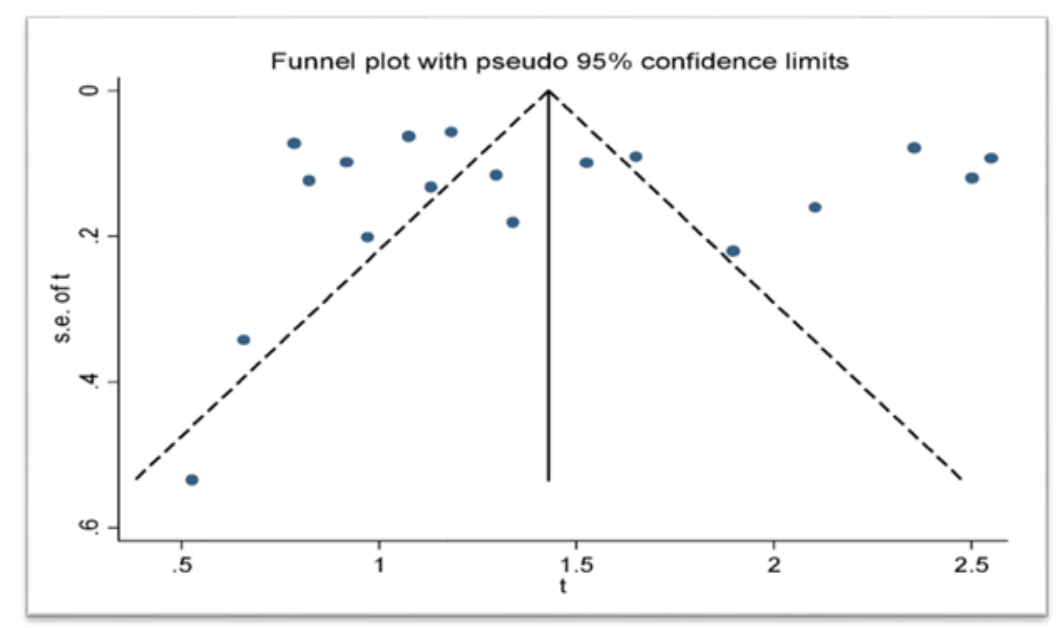

Figure 2. Funnel Plot of Arcsine Transformed Prevalence Estimates ( $t$ ) of HPV Recovered from the Uterine Cervix of Nigerian Women, 2019. 


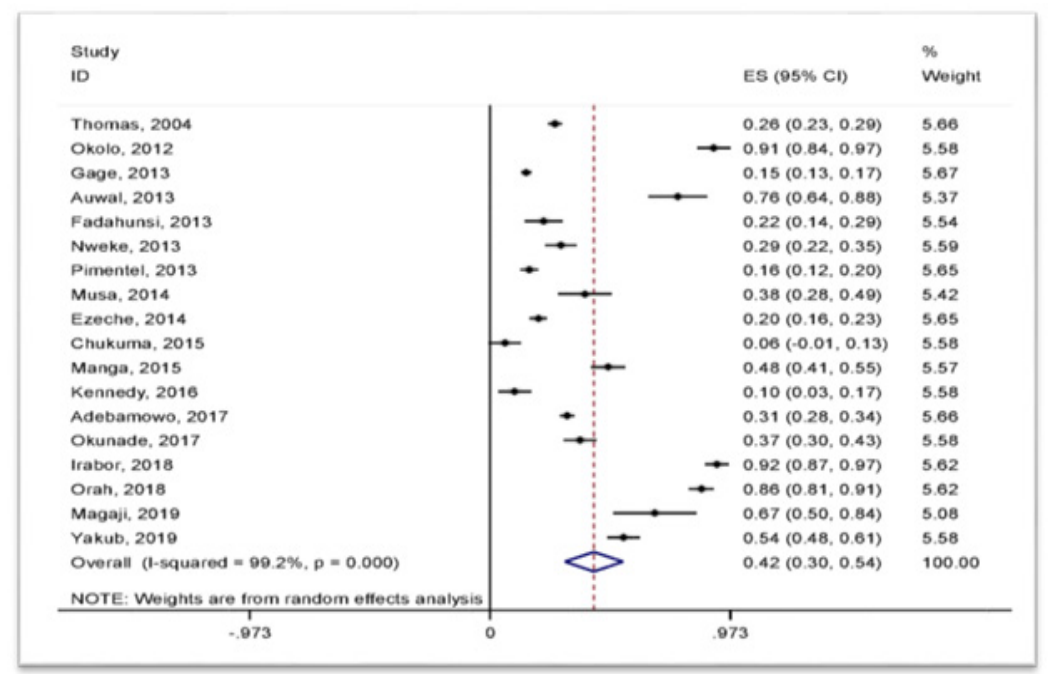

Figure 3. Forest Plots Indicating a Pooled Prevalence of Cervical HPV Infection in Nigeria, 2019. The overall pooled prevalence was $42 \%$ (95\% CI: $30-54 \%)$.

and 45. HPV-16 was predominantly recovered in HGSILs and cervical cancer with a prevalence of $51 \%$ (95\% CI: $33-$ $69 \%$ ), followed by genotype 18,45 , and 35 . Predominant genotypes in HIV positive were 35, 16, 58, 52, 45, 31, 33 and 18 (Table 3 ).

Association between risk factors and cervical HPV infection in Nigeria
Some included studies evaluated the potential factors thought to be associated with the acquisition of HPV infection. Our analyses indicated a statistically significant association with multiple sexual partners $[\mathrm{OR}=1.46$ (95\%CI: 1.19-1.8); $<<0.01]$ and HIV infection [OR $=2.34$ (95\%CI: 1.36-4.02); $\mathrm{p}<0.01]$. As indicated in Table 4, other indicators of sexual/reproductive behavior, literacy, place of residence, and CD4+ T-cell count showed various

Table 4. Subgroup Analysis by the Risk Factors

\begin{tabular}{|c|c|c|c|c|c|}
\hline Risk factor & Category & No of studies & Pooled OR $(95 \% \mathrm{CI})$ & $\mathrm{I}^{2}(\mathrm{p}$-value $)$ & Z-test p-value \\
\hline \multirow[t]{2}{*}{ Age (years) } & $<30$ & 5 & $1.44(0.88-2.35)$ & $47.9(0.10)$ & 0.14 \\
\hline & $\geq 30$ & & $0.69(0.43-1.13)$ & & \\
\hline \multirow[t]{2}{*}{ Age at sexual debut } & $<18$ & 2 & $1.47(0.72-2.99)$ & $77(0.04)$ & 0.29 \\
\hline & $\geq 18$ & & $0.68(0.33-1.38)$ & & \\
\hline \multirow[t]{2}{*}{ No of sexual partners } & $>1$ & 7 & $1.46(1.19-1.8)$ & $11.5(0.34)$ & $<0.01$ \\
\hline & 1 & & $0.68(0.56-0.84)$ & & \\
\hline \multirow[t]{2}{*}{ Parity } & $>4$ & 5 & $1.43(0.75-2.72)$ & $81.9(<0.01)$ & 0.28 \\
\hline & $\leq 4$ & & $0.70(0.37-1.33)$ & & \\
\hline \multirow[t]{2}{*}{ Husband having more than one sex partner } & Yes & 3 & $1.38(0.98-1.94)$ & $0(0.54)$ & 0.07 \\
\hline & No & & $0.73(0.51-1.02)$ & & \\
\hline \multirow[t]{2}{*}{ History or evidence of STIs other than HIV } & Yes & 3 & $3.05(0.95-9.73)$ & $87(<0.01)$ & 0.02 \\
\hline & No & & $0.33(0.1-1.06)$ & & \\
\hline \multirow[t]{2}{*}{ Use of barrier contraceptive } & Never use & 3 & $1.19(0.81-1.75)$ & $0(0.64)$ & 0.37 \\
\hline & Ever use & & $0.84(0.57-1.23)$ & & \\
\hline \multirow[t]{2}{*}{ Use of hormonal/oral contraceptive } & Ever use & 4 & $0.98(0.7-1.37)$ & $0(0.55)$ & 0.9 \\
\hline & Never use & & $1.02(0.73-1.43)$ & & \\
\hline \multirow[t]{2}{*}{ Place of residence } & Urban & 3 & $1.02(0.46-2.26)$ & $61.2(0.08)$ & 0.96 \\
\hline & Rural & & $0.98(0.44-2.18)$ & & \\
\hline \multirow[t]{2}{*}{ Literacy level } & Low & 4 & $1.34(0.63-2.86)$ & $69.6(0.02)$ & 0.45 \\
\hline & High & & $0.75(0.35-1.6)$ & & \\
\hline \multirow[t]{2}{*}{ HIV status } & Positive & 5 & $2.34(1.36-4.02)$ & $75.6(<0.01)$ & $<0.01$ \\
\hline & Negative & & $0.43(0.25-0.73)$ & & \\
\hline \multirow[t]{2}{*}{ CD4 cell count } & $<500$ & 2 & $16.46(0.2-1378.6)$ & $79.1(0.03)$ & 0.22 \\
\hline & $\geq 500$ & & $0.06(0-5.09)$ & & \\
\hline
\end{tabular}

OR, odds ratio; CI, confidence interval; $\mathrm{I}^{2}$, heterogeneity; STI, sexually transmitted infection; IUCD, intrauterine contraceptive device. 


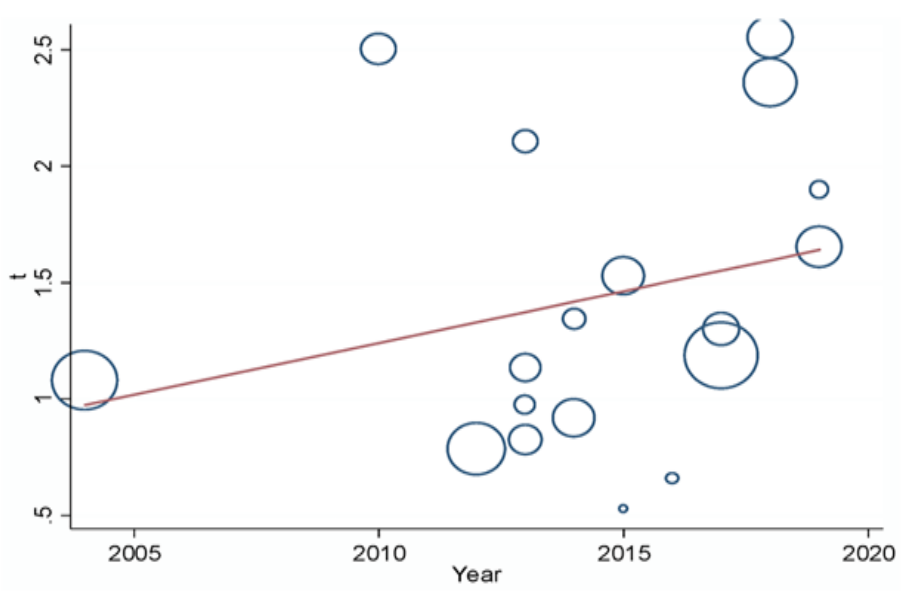

Figure 4. Meta-Regression of Cervical HPV Infection by Year, Nigeria, 2019.

forms of association.

\section{Meta-regression analysis}

Univariate Meta-regression analysis was performed to assess the pattern of cervical HPV infection among the included population by year of publication. Although as shown in Figure 4, there is evidence of an increase in the trend of the infection from 2004 to 2019, the increment has no statistical effect $($ coefficient $=0.0443924: p=0.292)$ (Figure 4)

\section{Discussion}

Epidemiological studies on prevalence and distribution of HPV infection are not just important in evaluating the impact of the existing cervical cancer screening and HPV vaccination programs but also provide the opportunity to explore other relevant tools to combat cervical cancer and other HPV related diseases. In Sub-Saharan Africa, there is significant regional variation in the incidence of HPV infection and cervical cancer, and the highest burden was observed in the East and Southern parts (De Vuyst et al., 2013). In Nigeria, data on cervical HPV infection are highly variable and incomplete. While studies conducted in hospitals remained the major source of data, in most cases the studies are designed by convenience of the researchers. Our study revealed a high prevalence of $42 \%$ (95\% CI: 30-54\%). However, the prevalence is lower than that in Rwanda (Ngabo et al., 2016), Zimbabwe (Dube Mandishora et al., 2017), Angola (de Almeida Damião et al., 2016), Gabon (Assoumou et al., 2016), South Africa (Ebrahim et al., 2016; Mbulawa et al., 2018), Swaziland (Ginindza et al., 2017) and Pakistan (Siddiqa et al., 2014) $\neg$, but higher than that in Cameroon (Doh et al., 2017), Ethiopia (Leyh-Bannurah et al., 2014), Gambia (Camara et al., 2018), The Demographic Republic of Congo (Mutombo et al., 2019), Chad (Bouassa et al., 2019), Bangladesh (Nahar et al., 2014), Tunisia (Guettiti et al., 2014), Islamic Republic of Iran (Kesheh and Keyvani, 2019), India (Sabeena et al., 2017), Nepal (Shakya et al., 2017) and China (Su et al., 2019). The fact that Nigeria is cosmopolitan with diverse ethnic groups and cultural practices, which in practice affect disease transmission and spread, may account for the high prevalence observed. Using different age categories, subgroup analysis demonstrated a bi-modal age-specific peak as was observed in previous studies (Castle et al., 2005; De Sanjosé et al., 2007; Mutombo et al., 2019; Su et al., 2019). This finding is not surprising considering the role of intergenerational sexual relationships in fueling the spread of sexually transmissible infections (Oyediran et al., 2011; Baussano et al., 2013; Mavhandu-Mudzusi et al., 2014; National Bureau of Statistics and Fund, 2017). In intergeneration marriage (a common practice in many parts of Nigeria), an infected older man is likely to infect his young-female-partner or acquire the infection and reintroduce to a woman who probably was infected with HPV and cleared the virus during her active sexual life. Perhaps, a young man having a sexual relationship with an infected older woman can acquire and transmit the virus to his younger partner, and vice-versa. An HPV naïve adolescent woman, due to fragile nature of her immune system, can acquire the infection from infected cowife(ves), since she is at crucial period of contacting many sexually transmitted infections. The highest prevalence of cervical HPV infection observed among adolescent and grown-up females matched with reports from other countries (Tricco et al., 2011; Bahmanyar et al., 2012; Ebrahim et al., 2016; Ginindza et al., 2017; Bouassa et al., 2019; Mutombo et al., 2019; Su et al., 2019). The results of a randomized control trial (Sankaranarayanan et al., 2009) suggested the reliability of PCR in detecting HPV DNA as used by the majority of the included studies. Nevertheless, studies employing serology, hybrid capture, cytology and SPF10/LIPA25 should not be discourage as they provide clues and guide clinical decision-making. Reflecting on the genotypes diversity, the high prevalence of oncogenic types might suggest increasing tendency for developing cervical cancer and high burden in Nigeria.

The fact that HIV positive women are more likely to acquire HPV has been demonstrated (Wang et al., 2015; Menon et al., 2016; Obiri-Yeboah et al., 2017). HIV is thought to favor the persistence of cervical HPV infection, which in turn results in precancerous lesions, and potentiate progression of the lesions to cancer (Ahdieh et al., 2001; Palefsky, 2003; Strickler et al., 2005). 
Furthermore, the lack of treatment for HPV infection and increase life expectancy in HIV infected individuals (due to availability of antiretroviral drugs) intensify the risk of developing high-grade cervical lesions and carcinomas (Cañadas et al., 2010; Cohen et al., 2019). Although several studies reported a higher prevalence of HPV in HIV positive women, the lower prevalence (37\%) observed in this study might be due to a small number of HIV positive women included as evidenced by the 95\% CI: $25-50 \%$. However, the variation observed in HPV genotypes distribution coincides with findings of previous reports (Menon et al., 2016; Obiri-Yeboah et al., 2017), highlighting the necessity of strict monitoring of HPV infection in women living with HIV/AIDS in Nigeria. Also, the association of HPV infection with multiple sexual partners and other sexually transmitted infections, long periods of and recurrent exposure to HPV oncogens increase the likelihhod of developing premalignant lesions and cervical cancer (Doh et al., 2017).

Moreover, immense disease burden and fragile health care system embedded in the broader context of poverty, underdevelopment, poor governance, political instability, internal conflicts, insecurity of lives and properties might explain the increasing incidence of HPV related diseases in Sub-Saharan Africa and some Asian countries. With these constraints, it is nearly impossible to achieve a sustainable cytology-based cervical cancer prevention program, talkless of making the HPV vaccines available and affordable.

In conclusion, this systematic review and metaanalysis illustrated a high prevalence and variation in the distribution of cervical HPV infection in Nigeria and identified HIV as a significant cofactor. In addition to HPV genotypes 16 and 18 , the study also identified a high burden of other oncogenic HPV variants that are not included in the first generation of HPV vaccines. The infections are mostly in teenagers and young adults and there is a second peak at the age of 50 years and above. Our findings suggested a comprehensive cervical cancer screening program, incorporating HPV testing as an additional triaging modality. To improve knowledge about HPV infection, prevention, and vaccine uptake, we recommend school-based campaigns and vaccination programs. There is also a need for incorporating HPV testing as part of the existing HIV prevention and treatment.

\section{Acknowledgments}

We acknowledge all kinds of support from Tehran University of Medical Sciences, particularly the International Campus. We sincerely appreciate all contributors for their support, contributions, and criticism. We thank the anonymous reviewers for their critical reviews and comments.

\section{References}

Adebamowo SN, Famooto A, Dareng EO, et al (2018). Clearance of type-specific, low-risk, and high-risk cervical human Papillomavirus infections in HIV-negative and HIV-positive women. J Glob Oncol, 4, JGO. 17.00129.

Adebamowo SN, Olawande O, Famooto A, et al (2017). Persistent low-risk and high-risk human papillomavirus infections of the uterine cervix in HIV-negative and HIVpositive women. Front Public Health, 5, 178.

AdegbesanOmilabu M, Okunade K, Omilabu S (2014). Oncogenic human papilloma virus infection among women attending the cytology clinic of a tertiary hospital in Lagos, South-West Nigeria. Int J Res Med Sci, 2, 625-30.

Ahdieh L, Klein RS, Burk R, et al (2001). Prevalence, incidence, and type-specific persistence of human papillomavirus in human immunodeficiency virus (HIV)-positive and HIV-negative women. $J$ Infect Dis, 184, 682-90.

Ajenifuja OK, Ikeri NZ, Adeteye OV, et al (2018). Comparison between self sampling and provider collected samples for Human Papillomavirus (HPV) Deoxyribonucleic acid (DNA) testing in a Nigerian facility. Pan Afr Med J, 30.

Akarolo-Anthony SN, Al-Mujtaba M, Famooto AO, et al (2013). HIV associated high-risk HPV infection among Nigerian women. BMC Infect Dis, 13, 521.

Akarolo-Anthony SN, Famooto AO, Dareng EO, et al (2014). Age-specific prevalence of human papilloma virus infection among Nigerian women. BMC Public Health, 14, 656.

Assoumou SZ, Mbiguino AN, Mabika BM, et al (2016). Human papillomavirus genotypes distribution among Gabonese women with normal cytology and cervical abnormalities. Infect Agents Cancer, 11, 2.

Audu B, Bukar M, Ibrahim A, et al (2014). Awareness and perception of human papilloma virus vaccine among healthcare professionals in Nigeria. J Obstet Gynaecol, 34, 714-7.

Auwal IK, Aminu M, Atanda A, et al (2013). Prevalence and risk factors of high risk human papillomavirus infections among women attending gynaecology clinics in Kano, Northern Nigeria. BAJOPAS, 6, 67-71.

Bahmanyar ER, Paavonen J, Naud P, et al (2012). Prevalence and risk factors for cervical HPV infection and abnormalities in young adult women at enrolment in the multinational PATRICIA trial. Gynecol Oncol, 127, 440-50.

Baussano I, Franceschi S, Gillio-Tos A, et al (2013). Difference in overall and age-specific prevalence of high-risk human papillomavirus infection in Italy: evidence from NTCC trial. BMC Infect Dis, 13, 238.

Bouassa R-SM, Nodjikouambaye ZA, Sadjoli D, et al (2019). High prevalence of cervical high-risk human papillomavirus infection mostly covered by Gardasil-9 prophylactic vaccine in adult women living in N'Djamena, Chad. PLoS One, 14, e0217486.

Bray F, Ferlay J, Soerjomataram I, et al (2018). Global cancer statistics 2018: GLOBOCAN estimates of incidence and mortality worldwide for 36 cancers in 185 countries. $C A$ Cancer J Clin, 68, 394-424.

Camara HB, Anyanwu M, Wright E, et al (2018). Human papilloma virus genotype distribution and risk factor analysis amongst reproductive-age women in urban Gambia. J Med Microbiol, 67, 1645-54.

Cañadas M, Videla S, Darwich L, et al (2010). Human papillomavirus HPV-16, 18, 52 and 58 integration in cervical cells of HIV-1-infected women. J Clin Virol, 48, 198-201.

Castle PE, Schiffman M, Herrero R, et al (2005). A prospective study of age trends in cervical human papillomavirus acquisition and persistence in Guanacaste, Costa Rica. J Infect Dis, 191, 1808-16.

Chukwuma G, Akujobi C, Ezeifeka G, et al (2015). Prevalence and possible risk factors for human papilloma virus among HIV infected women. Arch Bas App Med, 2015, 1-8.

Clarke MA, Gage JC, Ajenifuja KO, et al (2011). A population- 
based cross-sectional study of age-specific risk factors for high risk human papillomavirus prevalence in rural Nigeria. Infect Agents Cancer, 6, 12.

Cohen MS, Council OD, Chen JS (2019). Sexually transmitted infections and HIV in the era of antiretroviral treatment and prevention: the biologic basis for epidemiologic synergy. $J$ Int AIDS Soc, 22, e25355.

Dareng E, Ma B, Famooto A, et al (2016). Prevalent high-risk HPV infection and vaginal microbiota in Nigerian women. Epidemiol Infect, 144, 123-37.

de Almeida Damião P, Oliveira-Silva M, Moreira MÂ, et al (2016). Human Papillomavirus types distribution among women with cervical preneoplastic, lesions and cancer in Luanda, Angola. Pan Afr Med J, 24, 268.

De Sanjosé S, Diaz M, Castellsagué X, et al (2007). Worldwide prevalence and genotype distribution of cervical human papillomavirus DNA in women with normal cytology: a meta-analysis. Lancet Infect Dis, 7, 453-9.

De Vuyst H, Alemany L, Lacey C, et al (2013). The burden of human papillomavirus infections and related diseases in sub-saharan Africa. Vaccine, 31, 32-46.

Doh G, Ikomey GM, Njenda D, et al (2017). Oncogenic human papillomavirus genotypes 16 and 18 prevalence among women with normal cervical cytology and neoplasia in Cameroon: A Systematic Review. Cancer, 16, 32.

Dube Mandishora RS, Christiansen IK, Chin'ombe N, et al (2017). Genotypic diversity of anogenital human papillomavirus in women attending cervical cancer screening in Harare, Zimbabwe. J Med Virol, 89, 1671-7.

Ebrahim S, Mndende XK, Kharsany AB, et al (2016). High burden of human papillomavirus (HPV) infection among young women in KwaZulu-Natal, South Africa. PLoS One, 11, e0146603.

Ezechi OC, Ostergren PO, Nwaokorie FO, et al (2014). The burden, distribution and risk factors for cervical oncogenic human papilloma virus infection in HIV positive Nigerian women. Virol J, 11, 5.

Fadahunsi O, Omoniyi-Esan G, Banjo A, et al (2013). Prevalence of high risk oncogenic human papillomavirus types in cervical smears of women attending well woman clinic in Ile Ife, Nigeria. Gynecol Obstet, 3, 2161-0932.1000185.

Famooto A, Almujtaba M, Dareng E, et al (2013). RPS19 and TYMS SNPs and prevalent high risk human papilloma virus infection in Nigerian women. PLoS One, 8, e66930.

Ferlay J, Colombet M, Soerjomataram I, et al (2019). Estimating the global cancer incidence and mortality in 2018: GLOBOCAN sources and methods. Int J Cancer, 144, 1941-53.

Gage JC, Ajenifuja KO, Wentzensen N, et al (2012a). Effectiveness of a simple rapid human papillomavirus DNA test in rural Nigeria. Int J Cancer, 131, 2903-9.

Gage JC, Ajenifuja KO, Wentzensen NA, et al (2012b). The age-specific prevalence of human papillomavirus and risk of cytologic abnormalities in rural Nigeria: Implications for screen-and-treat strategies. Int J Cancer, 130, 2111-7.

Ginindza TG, Dlamini X, Almonte M, et al (2017). Prevalence of and associated risk factors for high risk human papillomavirus among sexually active women, Swaziland. PLoS One, 12, e0170189.

Guettiti H, Ennaifer E, Attia L, et al (2014). Pre-vaccination prevalence and genotype distribution of human papillomavirus infection among women from urban Tunis: a cross-sectional study. Asian Pac J Cancer Prev, 15, 9361-5.

Irabor GI, Akpan D, Aigbe E, et al (2018). Specific human papillomavirus genotypes isolated from cervical cancer specimens in Calabar, Nigeria. J Cancer Tumor Int, 2018, $1-11$.
Kennedy NT, Ikechukwu D, Goddy B (2016). Risk factors and distribution of oncogenic strains of human papilloma virus in women presenting for cervical cancer screening in Port Harcourt, Nigeria. Pan Afr Med J, 23, 85.

Kesheh MM, Keyvani HJIjop (2019). The prevalence of HPV genotypes in Iranian population: An Update. Iran J Pathol, 14, 197-205.

Kolawole O, Ogah J, Alabi O, et al (2015). Utilization of human papillomavirus DNA detection for cervical cancer screening in women presenting with abnormal cytology in Lokoja, Nigeria. Jundishapur J Microbiol, 8, e22620..

Kolawole OM, Olatunji KT, Durowade KA (2016). Molecular detection of human papillomavirus from abnormal cervical cytology of women attending a tertiary health facility in Ido-ekiti, southwest Nigeria. J Prev Med Hyg, 57, E86-90.

Levine OS, Bloom DE, Cherian T, et al (2011). The future of immunisation policy, implementation, and financing. Lancet, 378, 439-48.

Leyh-Bannurah S-R, Prugger C, de Koning MN, et al (2014). Cervical human papillomavirus prevalence and genotype distribution among hybrid capture 2 positive women 15 to 64 years of age in the Gurage zone, rural Ethiopia. Infect Agents Cancer, 9, 33.

Magaji SJ, Aminu M, Inabo HI, et al (2019). Spectrum of high risk human papillomavirus types in women in Kaduna State, Nigeria. Ann Afr Med, 18, 30.

Manga M, Fowotade A, Abdullahi Y, et al (2016). Comparative analysis of cervical human papillomavirus DNA testing and cytological findings among women presenting for "Pap" smear in a tertiary health centre in Northern Nigeria. Int $J$ Trop Dis Health, 2016, 1-8.

Manga MM, Fowotade A, Abdullahi YM, et al (2015). Epidemiological patterns of cervical human papillomavirus infection among women presenting for cervical cancer screening in North-Eastern Nigeria. Infect Agents Cancer, $10,39$.

Mavhandu-Mudzusi AH, Sandy PT, Francis TK (2014). Factors contributing to intergenerational sexual relationships among refugee girls in the city of Tshwane, South Africa. Mediterr J Soc Sci, 5, 2876.

Mbulawa ZZ, van Schalkwyk C, Hu N-C, et al (2018). High human papillomavirus (HPV) prevalence in South African adolescents and young women encourages expanded HPV vaccination campaigns. PLoS One, 13, e0190166.

Menon S, Wusiman A, Boily MC, et al (2016). Epidemiology of HPV genotypes among HIV positive women in Kenya: a systematic review and meta-analysis. PLos One, 11, $\mathrm{e} 0163965$.

Modibbo F, Iregbu K, Okuma J, et al (2017). Randomized trial evaluating self-sampling for HPV DNA based tests for cervical cancer screening in Nigeria. Infect Agents Cancer, $12,11$.

Moher D, Liberati A, Tetzlaff J, et al (2009). Preferred reporting items for systematic reviews and meta-analyses: the PRISMA statement. Ann Intern Med, 151, 264-9.

Musa J, Achenbach C, Taiwo B, et al (2014). High-risk human papilloma virus and cervical abnormalities in HIV-infected women with normal cervical cytology. Infect Agents Cancer, 9, 36 .

Musa J, Taiwo B, Achenbach C, et al (2013). High-risk human papillomavirus among HIV-infected women with normal cervical cytology: a pilot study in Jos, Nigeria. Arch Gynecol Obstet, 288, 1365-70.

Mutombo AB, Benoy I, Tozin R, et al (2019). Prevalence and distribution of human papillomavirus genotypes among women in Kinshasa, The Democratic Republic of the Congo. J Glob Oncol, 5, 1-9. 
Nahar Q, Sultana F, Alam A, et al (2014). Genital human papillomavirus infection among women in Bangladesh: findings from a population-based survey. PLoS One, 9, e107675.

National Bureau of Statistics, Fund UNCs (2017). Multiple Indicator Cluster Survey 2016-17, Survey Findings Report.

Nejo YT, Olaleye DO, Odaibo GN (2018). Prevalence and risk factors for genital human papillomavirus infections among women in Southwest Nigeria. Arch Bas App Med, 6, 105-12.

Ngabo F, Franceschi S, Baussano I, et al (2016). Human papillomavirus infection in Rwanda at the moment of implementation of a national HPV vaccination programme. BMC Infect Dis, 16, 225.

Nweke I, Banjo A, Abdulkareem F, et al (2013). Prevalence of human papilloma virus DNA in HIV positive women in Lagos University Teaching Hospital (LUTH) Lagos, Nigeria. Br Microbiol Res J, 3, 400-13.

Nyengidiki KT, Athanasius PB (2016). High risk human papilloma virus genotyping and cervical cytology as screening tests for cervical cancer in human immunodeficiency virus positive women in Nigeria. J Cancer Tumor Int, 2016, 1-7.

Nyengidiki T, Oranu E (2018). Pattern of cervical cytology and high risk human papillomavirus strains in non HIV positive women presenting for cervical cancer screening in port Harcourt, Nigeria. J Biosc Med, 6, 68-76.

Obiri-Yeboah D, Akakpo PK, Mutocheluh M, et al (2017). Epidemiology of cervical human papillomavirus (HPV) infection and squamous intraepithelial lesions (SIL) among a cohort of HIV-infected and uninfected Ghanaian women. BMC Cancer, 17, 688.

Okolo C, Franceschi S, Adewole I, et al (2010). Human papillomavirus infection in women with and without cervical cancer in Ibadan, Nigeria. Infect Agents Cancer, 5, 24.

Okunade KS, Nwogu CM, Oluwole AA, et al (2017). Prevalence and risk factors for genital high-risk human papillomavirus infection among women attending the outpatient clinics of a university teaching hospital in Lagos, Nigeria. Pan Afr Med J, 28, 227.

Oluwasola T, Bello O, Odukogbe AJTJoO, et al (2019). Awareness and attitude of female undergraduates toward human papillomavirus vaccine in Ibadan. Trop J Obstet Gynaecol, 36, 33-8.

Orah NO, Banjo AA (2018). Prevalence and distribution of high risk human papillomavirus subtypes in invasive cervical cancer in South-West Nigeria. Ann Trop Pathol, 9, 106.

Oyediran K, Odutolu O, Atobatele A (2011). Intergenerational sexual relationship in Nigeria: Implications for negotiating safe sexual practices. Social and Psychological Aspects of HIV/AIDS and their Ramifications, Prof. Gobopamang Letamo (Ed.), ISBN: 978-953-307-640-9, InTech, Available at :http://www.intechopen.com/books/social-andpsychological-aspects-of-hiv-aids-and-theirramifications/ intergenerational-sexual-relationship-in-nigeriaimplications-for-negotiating-safe-sexual-practices, pp 49-72.

Palefsky JM (2003). Cervical human papillomavirus infection and cervical intraepithelial neoplasia in women positive for human immunodeficiency virus in the era of highly active antiretroviral therapy. Curr Opin Oncol, 15, 382-8.

Pimentel VM, Jiang X, Mandavilli S, et al (2013). Prevalence of high-risk cervical human papillomavirus and squamous intraepithelial lesion in Nigeria. J Low Genit Tract Dis, 17, 203-9.

Sabeena S, Bhat PV, Kamath V, et al (2017). Communitybased prevalence of genital human papilloma virus (HPV) infection: a systematic review and meta-analysis. Asian Pac J Cancer Prev, 18, 145-54.

Sankaranarayanan R, Nene BM, Shastri SS, et al (2009). HPV screening for cervical cancer in rural India. $N$ Engl J Med, 360, 1385-94.

Schnatz PF, Markelova NV, Holmes D, et al (2008). The prevalence of cervical HPV and cytological abnormalities in association with reproductive factors of rural Nigerian women. J Womens Health, 17, 279-85.

Shakya S, Syversen U, Åsvold BO, et al (2017). Prevalence of human papillomavirus infection among women in rural Nepal. Acta Obstet Gynecol Scand, 96, 29-38.

Siddiqa A, Zainab M, Qadri I, et al (2014). Prevalence and genotyping of high risk human papillomavirus in cervical cancer samples from Punjab, Pakistan. Viruses, 6, 2762-77.

Strickler HD, Burk RD, Fazzari M, et al (2005). Natural history and possible reactivation of human papillomavirus in human immunodeficiency virus-positive women. $J$ Natl Cancer Inst, 97, 577-86.

Su Y, Yuan Z, Xu C, et al (2019). Prevalence and genotype distribution of human papillomavirus infection among women: A population-based study in Dali Bai Autonomous Prefecture, Yunnan Province, China. J Med Virol, 91, 1553-61.

Thomas J, Herrero R, Omigbodun A, et al (2004). Prevalence of papillomavirus infection in women in Ibadan, Nigeria: a population-based study. Br J Cancer, 90, 638.

Tricco AC, Ng CH, Gilca V, et al (2011). Canadian oncogenic human papillomavirus cervical infection prevalence: systematic review and meta-analysis. BMC Infect Dis, 11, 235.

Wang R, Guo X-1, Wisman GBA, et al (2015). Nationwide prevalence of human papillomavirus infection and viral genotype distribution in 37 cities in China. BMC Infect Dis, 15, 257.

Yakub MM, Fowotade A, Anaedobe CG, et al (2019). Human papillomavirus correlates of high grade cervical dysplasia among HIV-Infected women at a major treatment centre in Nigeria: a cross-sectional study. Pan Afr Med J, 33, 125.

\section{(ब) $\mathbb{0} \otimes$}

This work is licensed under a Creative Commons AttributionNon Commercial 4.0 International License. 